\title{
Effectiveness of Play Based Learning Activities in Improving Executive Function and Performance among Children with Attention Deficit Hyperactivity Disorder
}

\author{
Agraj $P^{1}$, Nevetha $S^{2}$ \\ ${ }^{1}$ The Tamilnadu Dr. M.G.R Medical University, JKKMMRF College of Occupational Therapy, Komarapalayam, \\ ${ }^{2}$ Associate Professor, JKKMMRF College of Occupational Therapy, Komarapalayam
}

\begin{abstract}
Aim: To determine the Effectiveness of play based learning activities in improving executive function and performance among children with ADHD. Objectives: To assess the level of executive function impairment and level of performance in children with $A D H D$ and to evaluate the Effectiveness of play based learning activities in improving executive function and performance among children with ADHD. Procedure: Totally 30 ADHD children (15 in control group and 15 in experimental group in the age group of 7-12 years) had participated in the current study. Both control and experimental groups are assessed using "Behavioral rating inventory of executive function (BRIEF)" and "Vanderbilt ADHD diagnostic teacher rating scale (performance part)". Experimental group received Occupational therapy treatment along with play based learning activities, control group received Occupational therapy treatment only. Result: Statistical significant is present in the experimental group with regard to the effectiveness of play based learning activities in improving executive function and performance among children with ADHD. Conclusion: play based learning activities have significant effect in improving executive function and performance among children with ADHD.
\end{abstract}

Keywords: ADHD, executive function, performance, play based learning activities, occupational therapy

\section{Introduction}

Attention-deficit hyperactivity disorder (ADHD) is one of the most frequently diagnosed and impairing neuro developmental disorders in childhood, with a prevalence of $3-5 \%$ in the general population of schoolchildren under 16 years, In community samples. ADHD characterized by hyperactivity, impulsivity, inattention. Children with ADHD often experiences executive function impairment such as problem with organization, flexibility, working memory, planning response inhibition, emotional regulation.

Many Students with ADHD have impaired working memory and some also have slow processing speed which is critical elements of executive function. These skills are critical for writing essays, working with maths problems, remembering what is read, and completing assignments.

65\% ADHD students have problem in the written expression, consequently writing essays, drafting book reports or answering questions on tests or homework is often challenging. That is the students often have difficulty in holding ideas in mind, acting upon and organizing the ideas, quickly retrieving grammar, spelling punctuation rules from long term memory, organizing the material in a logical sequence, and reviewing and correcting errors.

Play based activities is one of the method to promote learning and reduced behavioural issues in the child. Play based learning in school is about learning science and maths through discovery and developing language skills, fine and gross motor skills through meaningful play activities. Play based activities is associated with the intellectual skills and understandings. In play activity experiences, children integrate emotions, thinking and motivations that establish neural connections critical to effective brain functioning .During play activities imagination and imitation occurs which requires complex cognitive or intellectual processes. Development of cognitive skills including dispositions of learning memory, thinking skills, and language and literacy skills, have strong link to play activities.

Play activities are associated with development of social and emotional skills and understandings and assists children in building social skills that support positive relationships. it also help to teach the children how to regulate their behaviour, and understand others feelings. Through collaborating and cooperating in play activities, children learn how to negotiate and problems solve their personal dilemmas.

In this study the researcher intend to find out the effectiveness of play based learning activities in improving executive function and performance among children with ADHD.

\section{Literature Survey}

ADHD is a neurobehavioral disorder that typically begins in childhood and persists into adulthood. It is characterized by developmentally inappropriate levels of inattention and hyperactivity resulting in functional impairment in academic, family, and social settings. Children with ADHD may have trouble paying attention, controlling impulsive behaviours or be overly active.

The prevalence in school-aged children is estimated to between 8 and 11percent, making it one of the common 


\section{International Journal of Science and Research (IJSR) \\ ISSN (Online): 2319-7064}

Index Copernicus Value (2015): 78.96 | Impact Factor (2015): 6.391

disorders of childhood. In the National Survey of Children's Health (NSCH), the prevalence of parent-reported of ADHD among children aged 4-17 years of age in the United States was estimated to be 11percent. ADHD is more common on boys than girls (male to female ratio $4: 1$ for predominantly hyperactive type and 2:1 for the predominantly inattentive type). About $30-50 \%$ of people diagnosed in childhood continue to have symptoms into adulthood and between 2$5 \%$ of adults have the condition. The cause in majority of cases is unknown however it is believed to involve interaction between genetics, environmental factor and other factors. It affects about 6-7\% of children when diagnosed via the DSM-V Criteria and $1-2 \%$ when diagnosed via the ICD10 Criteria

Based on the presenting symptoms ADHD can be divided into three subtypes. They are: Predominantly inattentive, predominantly hyperactive impulsive, Combined type Symptoms of ADHD must begin by age six to twelve and be present for more than six months for a diagnosis to be made. In school aged individuals inattention symptoms often result in poor school performance. Children in community samples who shows symptoms of inattention, hyperactivity and impulsivity with or without formal diagnosis of ADHD also shows poor academic and educational outcomes.

An ADHD child often struggles with executive functioning which involves a pattern of chronic difficulties in executing daily tasks. Executive function is a process of higher brain functioning that is involved in goal directed activities. It is the part of the brain that enables people to make decisions and direct attention to certain areas in order to be successful in any given area. It is similar to an executive of a company who plans out how the resources of the company will be used, decides what the priorities are, decides what direction things will take in the long term and decides what to do when there is conflicting information. This is a process of understanding the concept that all actions cause a response or have a consequence. For most people executive functioning occurs without conscious thought and we improve as we mature. For some, however, they require explicit guiding to develop appropriate strategies to overcome their difficulty. Executive functioning deficits are not a diagnosis, but they make any other diagnosis that much more difficult to address.

\section{Methods}

The study setting of the research is Salem Institute of Rehabilitation, Salem. Sample sizes of 30 ADHD children were selected by convenient sampling. Play based activities are administrated. Total duration of study was 6 months.

\subsection{Materials}

\section{Behavioural rating inventory of executive function (BRIEF)}

The Behavioural Rating Inventory of Executive Function is an 86-item ecological rating scale (parent, teacher) designed to reflect the neuro psychological constructs of EF in everyday situations for children ages 5-18. It comprises eight scales, two indexes, and a Global Executive Composite. The Behavioural Regulation Index includes the
Inhibit, Shift, and Emotional Control scales, and the Metacognitive Index includes the Initiate, Working Memory, Plan- Organize, Organization of Materials, and Monitor scales. Internal consistency, test-retest reliability (.72.84).BRIEF requires $10-15$ minutes to administer; $15-20$ minutes to score by hand, software available for scoring and interpretation. Scoring is given 1, 2, 3 for the characteristics of never, sometimes, often respectively.

\section{Vanderbilt ADHD teacher rating scale}

The Vanderbilt scale is the initial assessment tool for measuring the frequency of the child's ADHD symptoms, and one measuring his or her performance in school and interactions with siblings with children ages of 6-12 years. The scale consist of 35 items that made up of 4 sub scale of inattention, hyperactivity, conduct/oppositional problems, anxiety problems. The estimates of the KR20 co-efficient for a binary item version of the scale ranged from 0.85 to 0.94 convergent validity with the SDQ was high (pear's correlation $>0.72$ ) for these 4 factors. For predictive validity the VADTRS produced a sensitivity of 0.69 , specificity of 0.84 , positive predictive value of 0.32 and negative predictive value of 0.96 .

First part measuring the frequency of the child's ADHD symptoms, and one measuring his or her performance in school and interactions with siblings.

The final 8 questions of both versions ask the respondent to rate the child's performance in school and his or her interactions with others on a 5 point scale, with1-2 meaning "problematic", 3 meaning "average" and 4-5 meaning "above average" each rating considered in the context of what is appropriate for the age of the children we are rating.

\subsection{Procedure}

Totally 30 subjects who met the selection criteria has included in this study. They are equally divided into control and experimental group by convenient sampling method. Both control and experimental groups are assessed using Behavioral rating inventory of executive function (BRIEF)and Vanderbilt ADHD diagnostic teacher rating scale(performance part). After the baseline data (pre-test) has obtained. The control group received only OT intervention whereas the experimental group underwent OT treatment with play based learning activities for 1 hour session per day for 3 months duration. After the intervention period is get over the post test was taken from both control and experimental group by using the same scales. The pretest and post test scores were used to find out the result of the study.

\subsection{Intervention}

Play based activities were administrated such as Block building, Connect four, Shape sorter, Mazes, Ludo board, Puzzles, Look and say, What comes next?, Boggle, Dots and boxes, Stacking cups, Tap tan, Word search, Spot the difference, Find missing, Drawing master, Spot observation, Craft, Card games "UNO", Categorising, Bubble wrap, Dot to dot (dot joining), Painting, Collage, Snake and ladder, Cutting and pasting, Go getter, Pick up stick 
International Journal of Science and Research (IJSR)

ISSN (Online): 2319-7064

Index Copernicus Value (2015): 78.96 | Impact Factor (2015): 6.391

\section{Data Analysis and Result}

Table 1: Comparison between pre-test values of control group and experimental group Behavioral Rating Inventory of Executive Function (BRIEF)

\begin{tabular}{|c|c|c|c|c|c|}
\hline Group & Test & Mean & $\begin{array}{c}\text { S.D } \\
\text { value }\end{array}$ & $\begin{array}{c}\text { 't' } \\
\text { value }\end{array}$ & $\begin{array}{c}p^{\prime} \\
\text { value }\end{array}$ \\
\hline Control group & Pre test & 195.40 & 15.40 & \multirow{2}{*}{0.2292} & 0.8221 \\
\hline Experimental group & Pre test & 196.60 & 14.02 & & \\
\hline
\end{tabular}

Table 1: shows the comparison of control group and experimental group pre-test mean value of BRIEF mean value $195.40,196.60$ and " $t$ " value is 0.2292 , "p" value is 0.8221 , which shows it is not statistically significant.

Table 2: Comparison between pre-test values of control group and experimental group Vanderbilt ADHD Rating Scale (Performance Part)

\begin{tabular}{|c|c|c|c|c|c|}
\hline Group & Test & Mean & $\begin{array}{c}\text { S.D } \\
\text { value }\end{array}$ & $\begin{array}{c}t ' \\
\text { value }\end{array}$ & $\begin{array}{c}p^{\prime} \\
\text { value }\end{array}$ \\
\hline Control group & Pre test & 24.87 & 4.73 & \multirow{2}{*}{0.2149} & 0.8330 \\
\hline Experimental group & Pre test & 24.53 & 4.29 & & \\
\hline
\end{tabular}

Table 2: shows the comparison of control group and experimental group pre test mean value of VANDERBILT mean value 24.87, 24.53 and "t" value is $\mathbf{0 . 2 1 4 9}$, "p" value is $\mathbf{0 . 8 3 3 0}$, which shows it is not statistically significant.

Table 3: Comparison between pre and post test values of control group Behavioral Rating Inventory of Executive Function (BRIEF)

\begin{tabular}{|c|c|c|c|c|c|}
\hline Group & Test & Mean & $\begin{array}{c}\text { S.D } \\
\text { value }\end{array}$ & $\begin{array}{c}\text { 't' } \\
\text { value }\end{array}$ & ' $p$ 'value \\
\hline Control group & Pre test & 195.40 & 15.40 & \multirow{2}{*}{7.3877} & $<0.0001$ \\
\hline Control group & Pre test & 189.00 & 16.37 & & \\
\hline
\end{tabular}

Table 3: shows the comparison of control group pre and post test mean value of BRIEF is $195.40,189.00$ and " $t$ " value is 7.3877, "p" value is $<0.0001$, which shows it is statistically significant.

Table 4: Comparison between pre and post test values of control group Vanderbilt

\begin{tabular}{|c|c|c|c|c|c|}
\hline Group & Test & Mean & $\begin{array}{c}\text { S.D } \\
\text { value }\end{array}$ & $\begin{array}{c}\text { 't' } \\
\text { value }\end{array}$ & 'p'value \\
\hline Control group & Pre test & 24.87 & 4.73 & 3.5555 & 0.0032 \\
\hline Control group & Pre test & 25.60 & 4.45 & 35 & \\
\hline
\end{tabular}

Table 4: shows the comparison of control group and experimental group pre and post test mean value of VANDERBILT is $24.87,25.60$ and " $t$ " value is 3.5555 , "p" value is 0.0032 , which shows it is statistically significant.

Table 5: Comparison between pre and post test values of experimental group-Behavior Rating Inventory of Executive Function (BRIEF)

\begin{tabular}{|c|c|c|c|c|c|}
\hline \multicolumn{1}{|c|}{ Group } & Test & Mean & $\begin{array}{c}\text { S.D } \\
\text { value }\end{array}$ & $\begin{array}{c}\text { 't' } \\
\text { value }\end{array}$ & $\begin{array}{c}p \\
\text { value }\end{array}$ \\
\hline Experimental group & Pre test & 196.60 & 14.02 & 12.6102 & 0.0001 \\
\hline Experimental group & Pre test & 155.33 & 13.95 & 12.00 & \\
\hline
\end{tabular}

Table 5; shows that comparative analysis of Experimental group pre-test and post test mean values of BRIEF is
$196.60,155.33$ and " $t$ " value is 12.6102 and " $p$ " value is 0.0001 .which shows it is statistically significant.

Table 6: Comparison between pre and post- test value of Experimental group VANDERBILT ADHD RATNG SCALE (PERFORMANCE PART)

\begin{tabular}{|c|c|c|c|c|c|}
\hline Group & Test & Mean & $\begin{array}{c}\text { S.D } \\
\text { value }\end{array}$ & $\begin{array}{c}\text { 't' } \\
\text { value }\end{array}$ & $\begin{array}{c}\text { 'p' } \\
\text { value }\end{array}$ \\
\hline Experimental group & Pre test & 24.53 & 4.29 & 6.3458 & 0.0001 \\
\hline Experimental group & Pre test & 28.80 & 3.67 & & \\
\hline
\end{tabular}

Table 6; shows that comparative analysis of Experimental group pre-test and post test mean values of VANDERBILT is 24.53,28.80 and " $t$ " value is 6.3458 and " $p$ " value is 0.0001.which shows it is statistically significant.

Table 7: Shows comparison between post test values of control group and Experimental group Behaviour Rating Inventory of Executive Function (BRIEF)

\begin{tabular}{|c|c|c|c|c|c|}
\hline Group & Test & Mean & $\begin{array}{c}\text { S.D } \\
\text { value }\end{array}$ & $\begin{array}{c}\text { ' } \text { ' } \\
\text { value }\end{array}$ & $\begin{array}{c}\text { 'p' } \\
\text { value }\end{array}$ \\
\hline Control group & Pre test & 189.00 & 16.37 & 5.9705 & 0.0001 \\
\hline Experimental group & Pre test & 155.33 & 13.95 & & \\
\hline
\end{tabular}

Table 7: shows comparison of control group and Experimental group post test mean value of BRIEF is $189.00,155.33$ and " $t$ " value is 5.9705, "P" value is 0.0001 , which shows it is statistically significant.

Table 8: shows comparison between post test values of control group and Experimental group. Vanderbilt ADHD Rating Scale (Performance Part)

\begin{tabular}{|c|c|c|c|c|c|}
\hline Group & Test & Mean & $\begin{array}{c}\text { S.D } \\
\text { value }\end{array}$ & $\begin{array}{c}\text { 't' } \\
\text { value }\end{array}$ & $\begin{array}{c}\text { 'p' } \\
\text { value }\end{array}$ \\
\hline Control group & Pre test & 25.60 & 4.5 & \multirow{2}{*}{5.0476} & 0.0002 \\
\hline Experimental group & Pre test & 28.80 & 3.67 & & \\
\hline
\end{tabular}

Table 8: Shows comparison of control and Experimental group post test mean value of VANDERBILT is 25.60,28.80 and " $\mathrm{t}$ " value is 5.0476, "P" value is 0.0002 , which shows it is statistically significant.

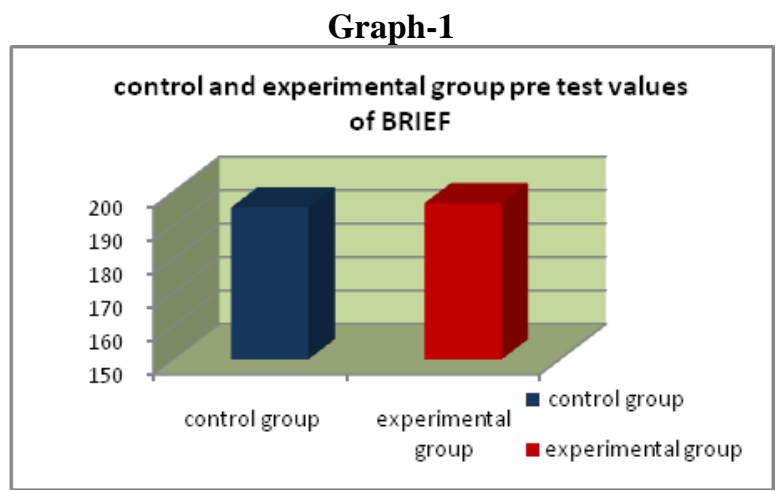

Comparison between pre-test values of control group and experimental group Behavioral Rating Inventory of Executive Function (BRIEF) 


\section{International Journal of Science and Research (IJSR) \\ ISSN (Online): 2319-7064}

Index Copernicus Value (2015): 78.96 | Impact Factor (2015): 6.391

Graph-2

Control and Experimental group pre test values of VANDERBILT

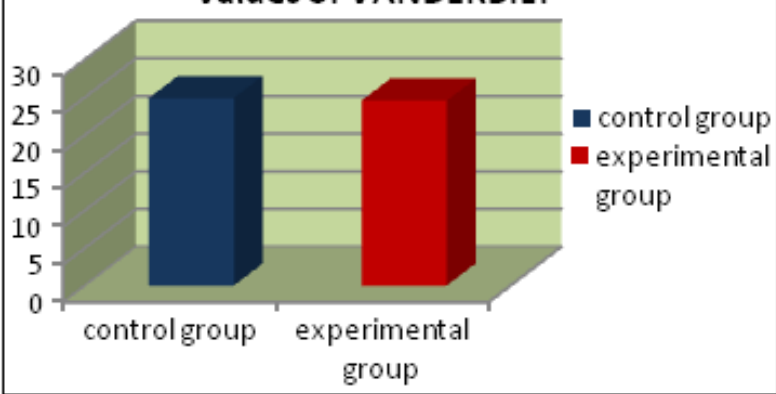

Comparison between pre-test values of control group and experimental group Vanderbilt ADHD Rating Scale (Performance Part)

Graph-3

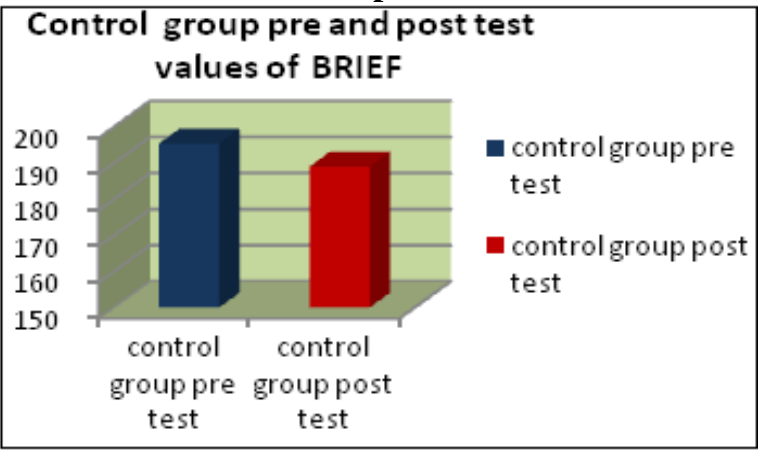

Comparison between pre and post test values of control group Behavioral Rating Inventory of Executive Function (BRIEF)

\section{Graph-4}

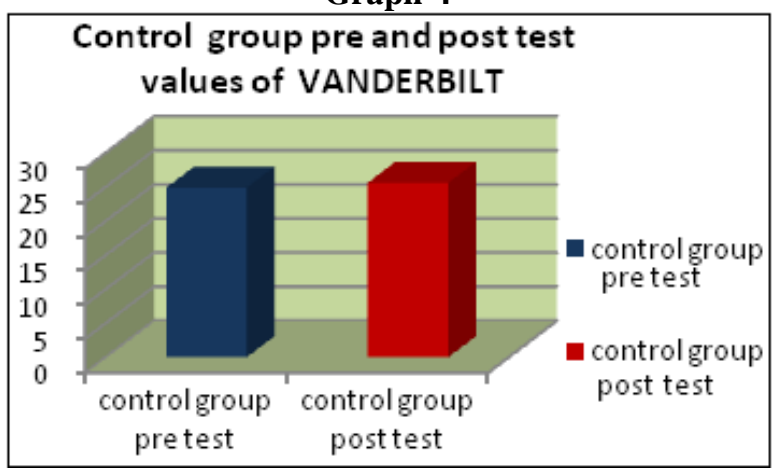

Comparison between pre and post test values of control group Vanderbilt

\section{Graph-5}

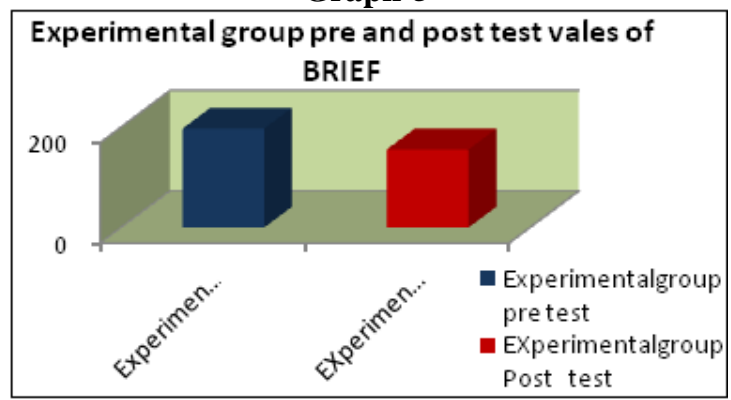

Comparison between pre and post test values of experimental group-Behavior Rating Inventory of Executive Function (BRIEF)
Graph-6

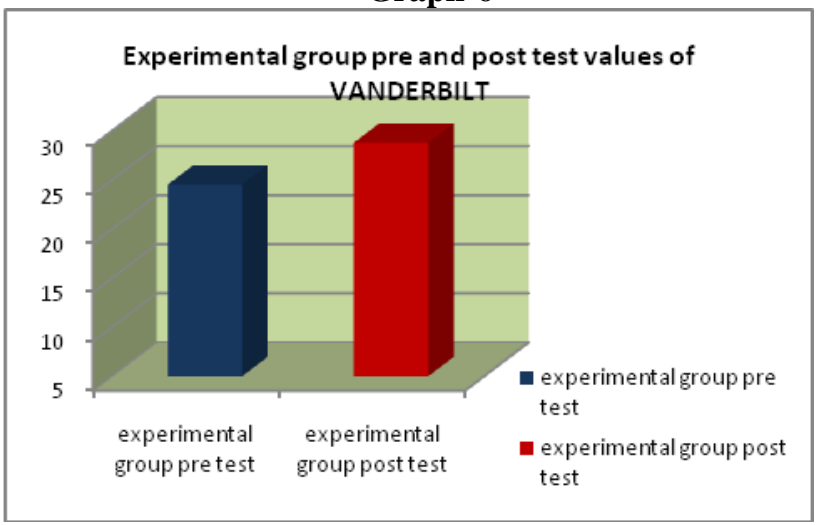

Comparison between pre and post- test value of Experimentalgroup VANDERBILT ADHD RATNG SCALE (PERFORMANCE PART)

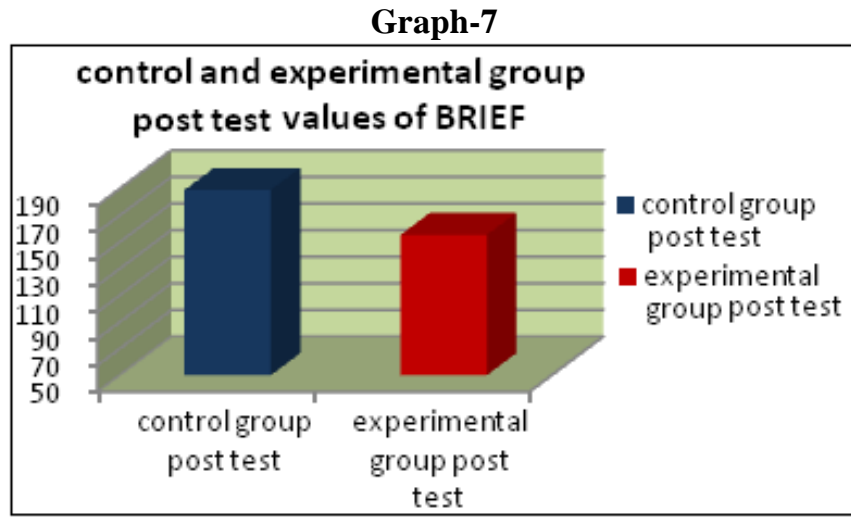

Comparison between post test values of control group and Experimental group Behavior Rating Inventory of Executive Function (BRIEF)

Graph-8

Control and Experimental group post test values of VANDERBILT

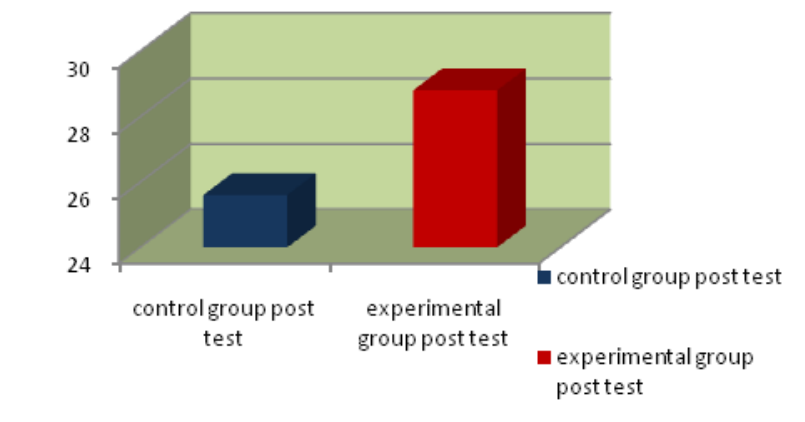

comparison between post test values of control group and Experimental group. Vanderbilt ADHD Rating Scale (Performance Part)

\section{Discussion}

The purpose of the study is to determine the effectiveness of play based learning activities in improving executive function and performance among children with ADHD.

Behavior Rating inventory of Executive function (BRIEF) and Vanderbilt ADHD Teacher Rating Scale (performance part) is the pretest and post test measurement tool. These 


\section{International Journal of Science and Research (IJSR) \\ ISSN (Online): 2319-7064}

Index Copernicus Value (2015): 78.96 | Impact Factor (2015): 6.391

scales are used to evaluate the impairment of executive function and level of performance among children with ADHD.

Initially the children with ADHD who are selected based on the inclusion criteria are assessed using the Behavior Rating Inventory of executive Function (BRIEF) and Vanderbilt ADHD Teacher Rating Scale (performance part) to get the pretest values. Play based learning activities are administered for three months, 3 sessions per week in alternative days each session last for 1 hour and after three months the post test values were collected and tabulated.

Table 1: Graph 1: shows that comparison between BRIEF control and experimental group pretest score mean values $195.40,196.60$; and ' $t$ ' value is 0.2292 , ' $p$ ' value is 0.8221 , the table value is 2.05 the $\mathrm{t}$ value is lesser than the table value, which shows it is not statistically significant and there is no difference between pretest values of control and experimental group.it denotes the subjects in control and experimental group shows same level of executive functional impairment.

Table 2: Graph 2: shows comparison between Vanderbilt (performance part) control and experimental group pretest score mean values $24.87,24.53$ and ' $t$ ' value is 0.2149 , ' $p$ ' value is 0.8330 , the table value is 2.05 ; the ' $t$ ' value is lesser than the table value, which shows it is not statistically significant and there is no difference between pretest values of control and experimental group. It denotes the subjects in control and experimental group shows same level of performance in pretest.

Table 3: Graph 3: shows comparison between BRIEF control pretest and post test scores the mean values are 195.40, 189.00 , respectively and t value is 7.3877 And $\mathrm{p}$ value is $<0.0001$ and the corresponding table value is 2.15 , hence the calculated $t$ value is greater than table value. It shows significant difference between pre and post test value of BRIEF control group. It shows the OT intervention is effective in decreasing executive functional impairment among children with ADHD.

Table 4: Graph 4; shows comparison between Vanderbilt control group pretest and post test scores the mean values 24.87 and 25.60 respectively $t$ value is 3.555 and $p$ value is 0.0032 and the corresponding table value is 2.15 hence the calculated $t$ value is greater than table value it shows there is an extremely significant difference between pre and post test value of Vanderbilt control group. it shows O.T intervention is effective in improving level of performance among children with ADHD.

Table 5: Graph 5. shows comparison between BRIEF experimental group pretest and post test scores the mean values are 196.60, 155.31, respectively and $t$ value is 12.6102 and the p value is 0.0001 and the corresponding table value is 2.15 hence the calculated $t$ value is greater than the table value it shows there is an extremely significant difference between pretest and posttest value of BRIEF experimental group. So the experimental group has significant improvement. Since the experimental group post test value is lesser than pretest value it shows executive functional impairment of ADHD is reduced in experimental group after intervention. That is OT combined with play based learning activities is effective in reducing the executive functional impairment in ADHD children.

These results are supported by the study done by

Elhamforozandeh, et al -2014

Study was conducted to evaluate the effect of play therapy on visual memory as one of the executive function in ADHD children. The participants of the study were 22 ADHD children randomly divided into control and experimental group.( control12 experimental 10) the experimental were under play therapy in 8 sessions each sessions lasts 30-45 minutes. The result indicated that play therapy was effective in improving visual memory of ADHD children.

Table 6: Graph 6. shows the comparison between Vanderbilt (performance section) experimental group pretest and posttest scores the mean values are $24.53,28.80$ respectively and $\mathrm{t}$ value is 6.3458 , the $\mathrm{p}$ value is 0.0001 and the corresponding table value is 2.15 hence the calculated t value is greater than the table value it shows there is extreme significant difference between pre and post test value of Vanderbilt experimental group. Since the post test mean value is greater than pre-test mean value. It denotes the children level of performance is increased. That is OT combined with play based learning activities is effective in improving level of performance among children with ADHD.

These results are supported by the study done by Safiadoutmani 2013. Study was conducted to find out the effectiveness of game based learning activities in children with ADHD. In this study ADHD children in the grades 6 to 8 were included in this study. Research suggest that students with ADHD children more able to focused when engaged in games . Game based learning has the potential to transform classrooms . Improving experience all students, research shows that students with ADHD respond well to games based learning activities

Table 7: Graph 7: shows comparison between BRIEF control and experimental post test score mean value 189.00, 155.33 respectively $\mathrm{t}$ value is 5.9705 and $\mathrm{p}$ value is 0.0001 and the corresponding table value is 2.05 , hence the calculated $t$ value is greater than table value. It shows there is significant difference between post test values of control and experimental group of BRIEF. Since the experimental group post test mean value is lesser than the control group children .it shows OT intervention along with play based learning activities is reducing executive functional impairment among ADHD.

These results are supported by the study done by Baduk. Study was conducted to evaluate effectiveness of playing go on cognitive function among ADHD. ADHD symptoms are associated with deficits in executive function. 17 ADHD students were participated. Studies have revealed that playing of board games such as GO or CHESS is related to executive function and problem solving skills. The study concluded that playing GO would be effective in children with ADHD by activating hypo arousal prefrontal function and enhancing executive function.

\section{Volume 6 Issue 7, July 2017 www.ijsr.net}




\section{International Journal of Science and Research (IJSR) \\ ISSN (Online): 2319-7064}

Index Copernicus Value (2015): 78.96 | Impact Factor (2015): 6.391

Table 8: Graph 8: shows comparison between Vanderbilt (performance section) control and experimental post test score mean value $25.60,28.80$ respectively $t$ value is 5.0476 and $\mathrm{p}$ value is $<0.0001$ and the corresponding table value is 2.05 hence the calculated $t$ value is greater than table. It shows there is an significant difference between post test value of control and experimental group of Vanderbilt .since the experimental group post test mean value is higher than the control group post test mean value,it denotes experimental group children increased in the level of performance more than control group children. It shows that the experimental group children improved in their level of performance. it shows OT intervention along with play based learning activities is effective in improving level of performance in children with ADHD more than OT intervention alone.

\section{A Bakhshayesh et al -2015}

This study evaluates the effectiveness of play therapy on the reduction of children's severity symptoms with ADHD and promotions of their academic performance.45 ADHD children in the age group of 7-11 years are included for this study. The severity of ADHD symptoms assessed by Conner's Rating scale and their academic performance were evaluated using the course grade. Result showed that play therapy increased children's academic performance and reducing severity of ADHD symptoms.

There is a significant improvement in experimental group after the administration of play based learning activities. The play based learning activities was provided only to experimental group, which shows high significant improvement in reducing the impairment of executive function and improving the level of performance, thus proving the alternate hypothesis and rejecting the null hypothesis. So the findings suggest that the play based learning activities was found to be effective in improving executive function and level of performance among children with ADHD.

\section{Result}

Statistical significant is present in the experimental group with regard to the effectiveness of play based learning activities in improving executive function and performance among children with ADHD

\section{Conclusion}

play based learning activities along with Occupational therapy intervention reduce executive functional impairment and improving level of performance among children with $\mathrm{ADHD}$ and play based activities are more attractive to the children and increase their active participation.

\section{Limitation and Recommendation}

Limitation such as Study is done with a limited sample size and only done for a confined age group, Not compared with genders and other treatment methods and Study is done for a short duration of time.
Recommendation such as The study can be done on a large sample size and follow up can be recommended. The study can be suitable if done with extended age limit and comparison between the genders and other treatment techniques includes.

\section{References}

[1] Braingame Brian. Toward an Executive Function Training Program with Game Elements for Children with ADHD and Cognitive Control Problems

[2] ElhamForoozandehMaliheMahdieh -2014 Effect of Play Therapy on Visual Memory in ADHD children International Journal of Sport Studies. Vol., 4 (8), 10051009, 2014

[3] Fazal Ghafoor1, K Firoz, Barkley, R. A. (2012). Executive Functioning and Self-Regulation: Extended Phenotype, Synthesis, and Clinical Implications. New York: Guilford Publications.

[4] Integration and Deployment of Educational Games in eLearning Environments: The Learning Object Model Meets Educational Gaming. Educational Technology \& Society, 12 (4), 359-371.

[5] International Journal of Psychology and Behavioral Research. Vol., 3(6), 485-498, 2014

[6] John R . Best ,2000 Relationship between executive function and academic achievement

[7] Joseph Biederman, Michael Impact of Executive Function Deficits and Attention-Deficit/Hyperactivity Disorder (ADHD) on Academic Outcomes in Children .Journal of Consulting and Clinical Psychology 2004, Vol. 72, No. 5, 757-76

[8] Journal of Child Psychology and Psychiatry 45:2 (2004), pp 284-292 Executive functioning in children: a comparison of hospitalised ODD and ODD/ADHD children and normal controls Stephanie H.M. van Goozen,1,2,3 Peggy T. Cohen-Kettenis,1,2 Heddeke Snoek, 1,2

[9] Laura L. Brocka,*, Sara E. Rimm-Kaufmana The contributions of 'hot' and 'cool' executive function to children's academic achievement, learning-related behaviors, and engagement in kindergarten

[10] McCandless 2007 deficits in executive functioning are responsible for the symptom of ADHD and that specific patterns of executive function deficits may be associated with different subtypes of ADHD .

[11]Rebecca Shaw and Vicky Lewis -2005computermediated communication, ADHD performance and behaviour. Journal of Research in Special Educational Needs • Volume $5 \cdot$ Number $2 \cdot 2005$

[12] Russell A. Barkley, Ph.D. The Important Role of Executive Functioning and Self-Regulation in ADHD

[13] SafiaDoumani -2013 Game-Base Learning and Attention Deficit Hyperactivity Disorder. California State University San Marcos Spring, 2013

[14] SalarFaramarzi; Maryam Ahmadzadeh -2014 The Effectiveness of Attention Games on Reduction of Executive Functions Deficits in Boys with Attention Deficit and Hyperactivity Disorder (ADHD): A SingleSubject Research International Journal of Psychology and Behavioral Research. Vol., 3(6), 485-498,

[15] Thomas et,al-2009 high IQ adults diagnosed with ADHD suffer from executive function (EF) impairments 


\section{International Journal of Science and Research (IJSR) \\ ISSN (Online): 2319-7064}

Index Copernicus Value (2015): 78.96 | Impact Factor (2015): 6.391

[16] Torrente, J., Moreno-Ger, P., Martínez-Ortiz, I., \& Fernandez-Manjon, B. (2009).

\section{Author Profile}

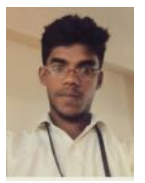

Agraj $\mathbf{P}$ is presently studying in final year bachelor of occupational therapy at jkk munirajah medical research foundation, collage of occupational therapy under the tamilnadu Dr, MGR Medical University, Chennai.

Nevetha $\mathbf{s}$ is presently working as Associate professor, JKKMMRF College of Occupational Therapy, Komarapalayam under the tamilnadu Dr, MGR Medical University, Chennai. 